\title{
Symptomatic Schizophrenia with Moya Moya Disease
}

\author{
GERARD MaDADE \\ University Hospital of South Manchester, West Didsbury, Manchester, M20 8LR, England \\ Correspondence and reprints: G. McDade, David Lewis Centre for Epilepsy, Mill Lane, Warford, \\ Nr Alderley Edge, Cheshire, SK9 7UD
}

\begin{abstract}
A young man with Moya Moya disease diagnosed in childhood following two episodes of transient hemiplegia, presented 12 years later with a schizophrenialike psychosis.

A causal link is suggested on the basis of the main site of the cerebral lesion.
\end{abstract}

\section{Introduction}

Schizophrenia secondary to organic brain damage, especially of the temporal lobe, is well described (Davison and Bagley, 1969; Davison, 1983). Moya Moya is a rare vascular disease more commonly found among the Japanese, with a characteristic angiographic appearance of widespread cerebral collaterals due to occlusion of one or both internal carotid arteries (Suzuki et al., 1969).

The aetiology is uncertain and it is assumed to be related to an acquired lesion of the blood vessels at the base of the brain. The association of schizophrenia with Moya Moya has not been described to date.

\section{Case Report}

A nineteen-year-old Asian boy who was born in this country presented with a 2 week history of bizarre behaviour and persecutory delusions, believing that his house was about to be bombed. He had fled his house on this account. His mother noted that he had been more solitary and moody, with a disturbed sleep pattern, over the same period. The paternal grandfather, who was very critical of the patient, had been visiting the family prior to this episode.

Developmentally, his birth and early years were unremarkable, but he was noted to have learning difficulties after attending a normal school for one year. He had a transient right hemiplegia at the age of 6 but was not hospitalized. He suffered a dense right hemiplegia at the age of 7 and underwent bilateral cerebral angiography shortly afterwards. This was reported as showing arterial spasm affecting the main intra-cranial arteries but there was a widespread complex vasular anastomosis especially affecting the left temporal and parietal regions. The overall appearance was charac- 
teristic of Moya Moya disease. No underlying cause was found and he made a full recovery without demonstrable neurological signs at follow up.

He subsequently attended a school for moderate learning difficulties. An IQ at the age of 7 gave a global score of 60 on the Wechsler Scale.

His family history is significant in that his father died aged 46 from a subarachnoid haemorrhage with proven Moya Moya disease. He has a 32year-old brother who had a hemiplegia in childhood but was not investigated. His 24-year-old sister developed "paralysis" at 18 months old and is now totally dependent on institutional care. Angiography has not been performed. Ten years ago his 33-year-old sister had a brief reactive psychosis during the period of her father's terminal illness and her impending divorce. She is now asymptomatic without medication. There is no other family history of psychological illness.

Premorbidly, his mother described him as a gregarious, industrious, good natured youth. There was no suggestion of drug abuse and he was not on any therapy on admission.

Mental state examination showed him to be dressed in pseudo-military uniform, he was co-operative during the interview and showed incongruity of affect when describing his persecutory ideas. There was no evidence of a mood disorder. He had marked formal thought disorder and believed his younger brother was a pilot. He had auditory hallucinations and described male and female voices which told him "to avoid machinery". He stated that his mind and thoughts were controlled by the television.

On physical examination he was right handed and had mild right upper motor neurone signs. There were no parietal lobe signs and his gait was clumsy.

Investigations showed that his full blood count was normal, routine biochemical screening was normal, he was euthyroid and his chest X-ray was clear.

Computerized Axial Tomography showed chronic loss of cortex in the left temporal/parietal and occipital lobes with under development of the left middle cranial fossa. There was a small area of low density in the right posterior parietal region but no evidence of recent intracranial abnormality (Fig 1).

EEG showed generalized paroxysms of theta activity arising from subcortical mid-line structures but no localized abnormality.

Psychometric testing showed little change in his global IQ at 65 (verbal scale 65, performance scale 65).

He satisfied the research diagnostic criteria (Spitzer et al., 1975) requirements for schizophrenia and was commenced on chlorpromazine. He lost all delusions within 2 weeks and at follow up 2 years later he remains well but tends to deteriorate if medication is reduced.

\section{Discussion}

A schizophrenia-like illness in this patient without a family history of the disease (or a schizoid personality) in the context of damage to the left 


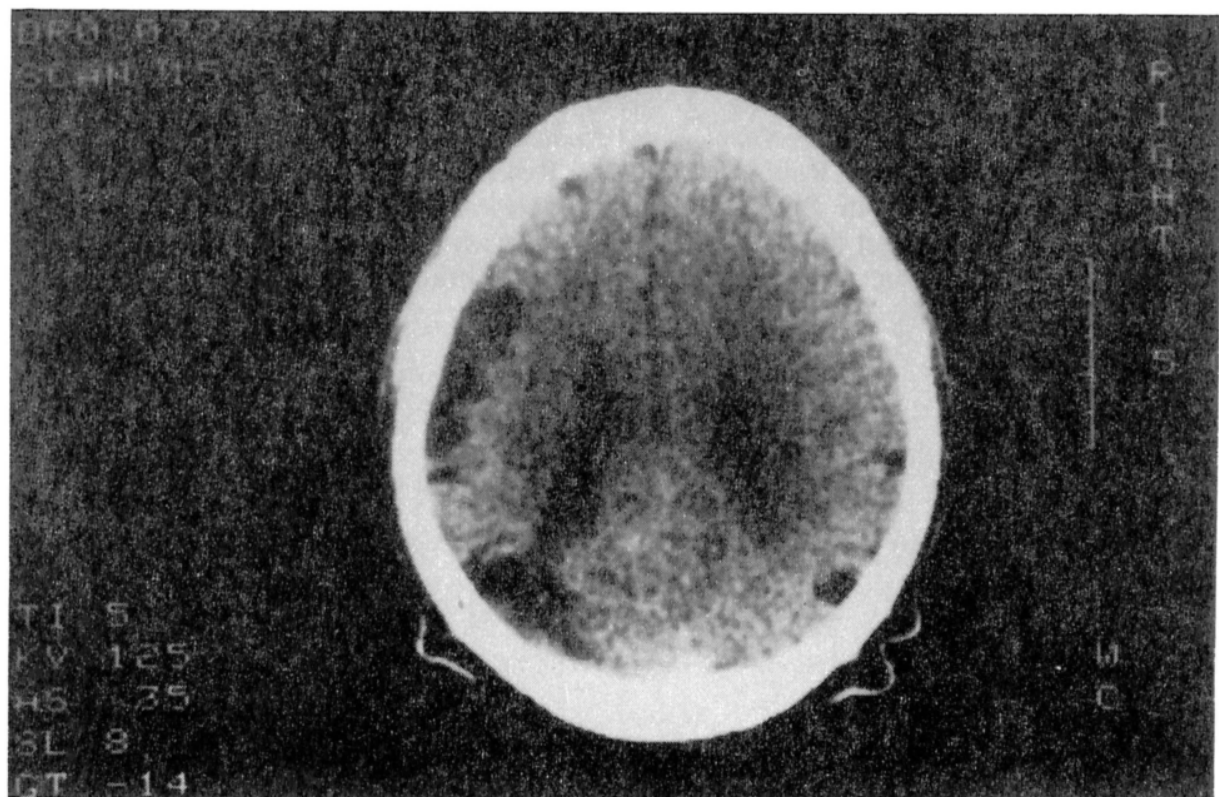

FIG. 1. C.T. scan showing loss of cortex in the left temporal/parietal region.

temporal and parietal lobes suggests a symptomatic schizophrenia. The schizophrenia-like illness associated with brain damage is phenomenologically indistinguishable from "nuclear" schizophrenia, although paranoid forms are said to predominate (Lishman, 1987).

The site of the lesion in the left temporal lobe corresponds with the observations of Flor-Henry (1969) and Davison and Bagley (1969) that dominant hemisphere lesions are more likely to produce a schizophrenia-like illness. Review of the literature reveals very little information on psychiatric sequelae of Moya Moya. A single case complicated by depression (Leksowski and Matysiakiewicz, 1981); has been described but there are no previous reports of the association of Moya Moya with schizophrenia.

\section{Acknowledgement}

I wish to thank Dr G. G. Hay for his help and encouragement in publishing this report of a patient under his care.

\section{References}

Davison, K. and Bagley, C. R. (1969). Schizophrenia-like psychosis associated with organic disorders of the central nervous system: A review of the literature. British Fournal of Psychiatry. Special Publication, 4, 113-184.

Davison, K. (1983). Schizophrenic-like psychosis associated with organic cerebral disorders: A Review. Psychiatric Developments, i, 1-34.

Flor-Henry, P. (1969). Psychosis and Temporal Lobe Epilepsy: A controlled investigation. Epilepsia, 10, 363-395. 
Lishman, W. A. (1987). In "Organic Psychiatry: The Psychological Consequences of Cerebral Disorder," 2nd Edn. Blackwell Scientific Publications, Oxford, pp. 74-77.

Leksowski, W. and Matysiakiewicz, J. (1981). Case of Moya Moya complicated by depression. Polish Fournal of Neurology and Neurosurgery, 15, 59-51.

Spitzer, R., Endicott, J. and Robbins, E. (1975). Research Diagnostic Criteria. Instrument No. 58, New York State Psychiatric Institute, New York.

Suzuki, J., Takaku, A. and Japan, S. (1969). Cerebrovascular Moya Moya disease; Disease showing abnormal net-like vessels in the base of the brain. Archives of Neurology, 20, 228229. 


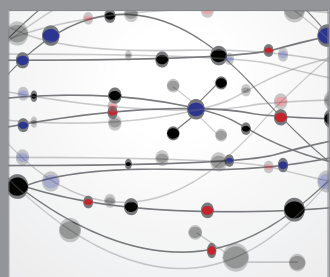

The Scientific World Journal
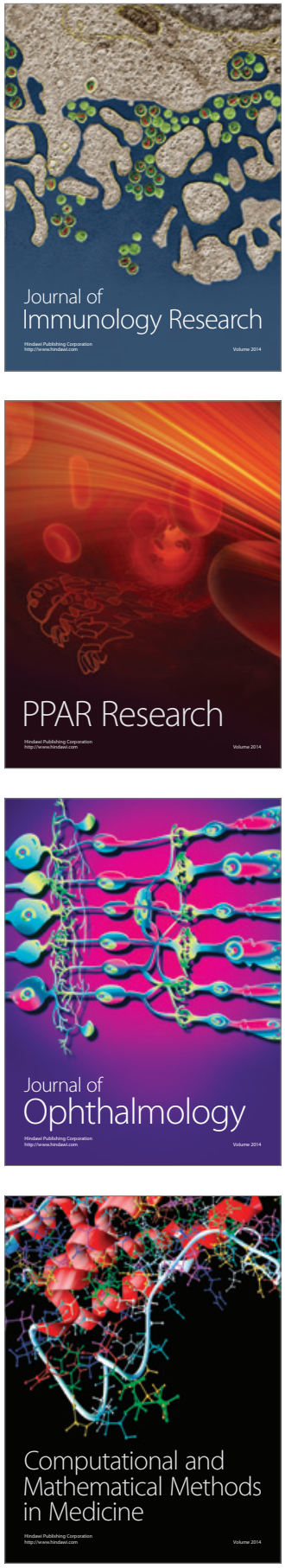

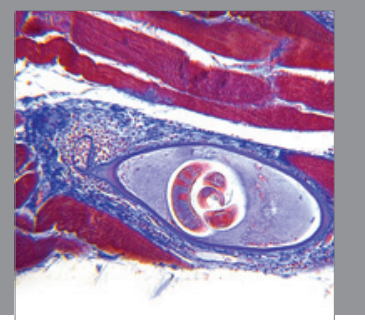

Gastroenterology

Research and Practice
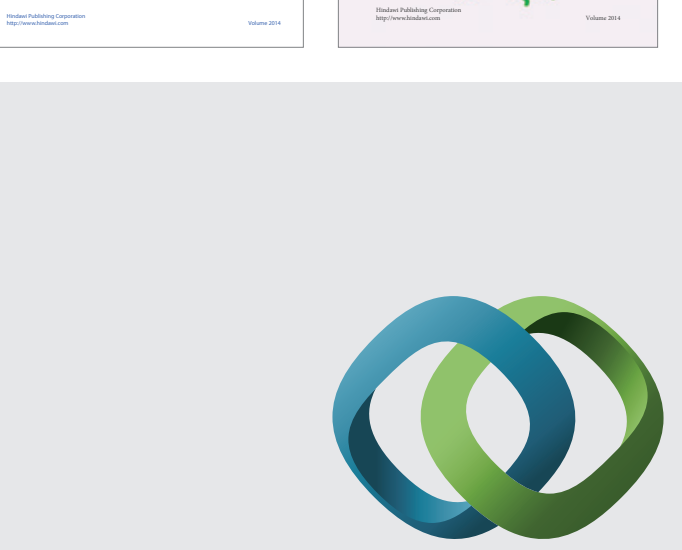

\section{Hindawi}

Submit your manuscripts at

http://www.hindawi.com
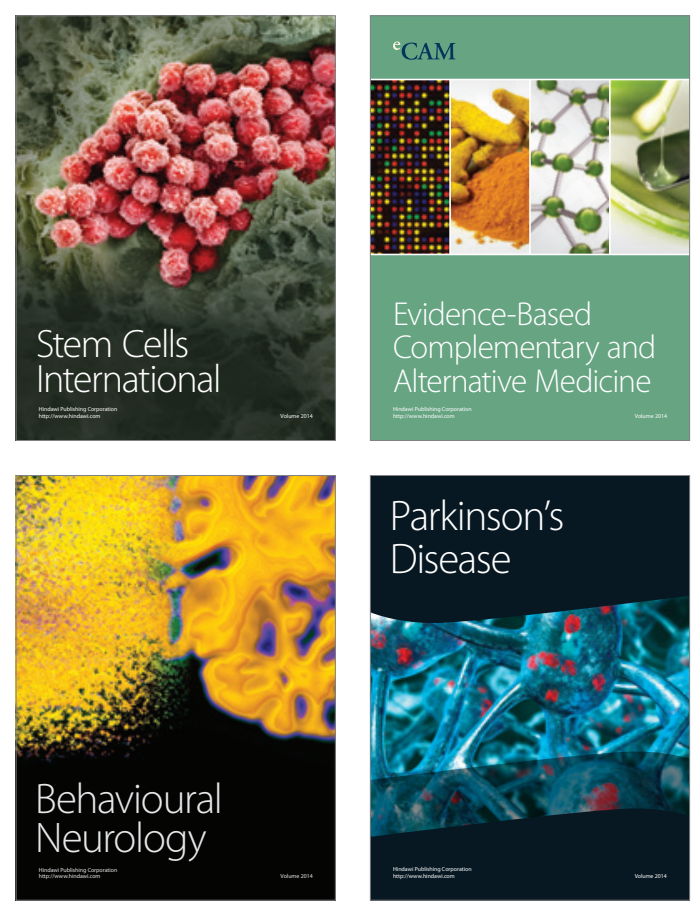

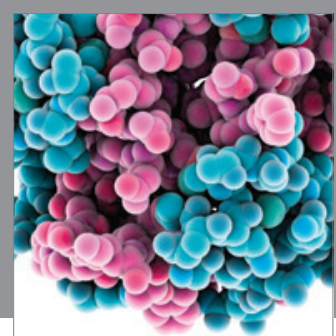

Journal of
Diabetes Research

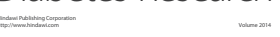

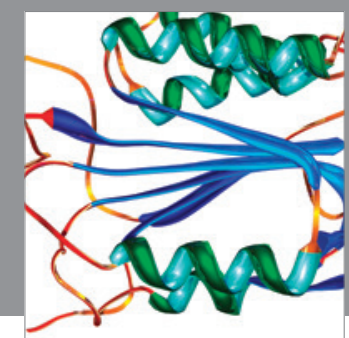

Disease Markers
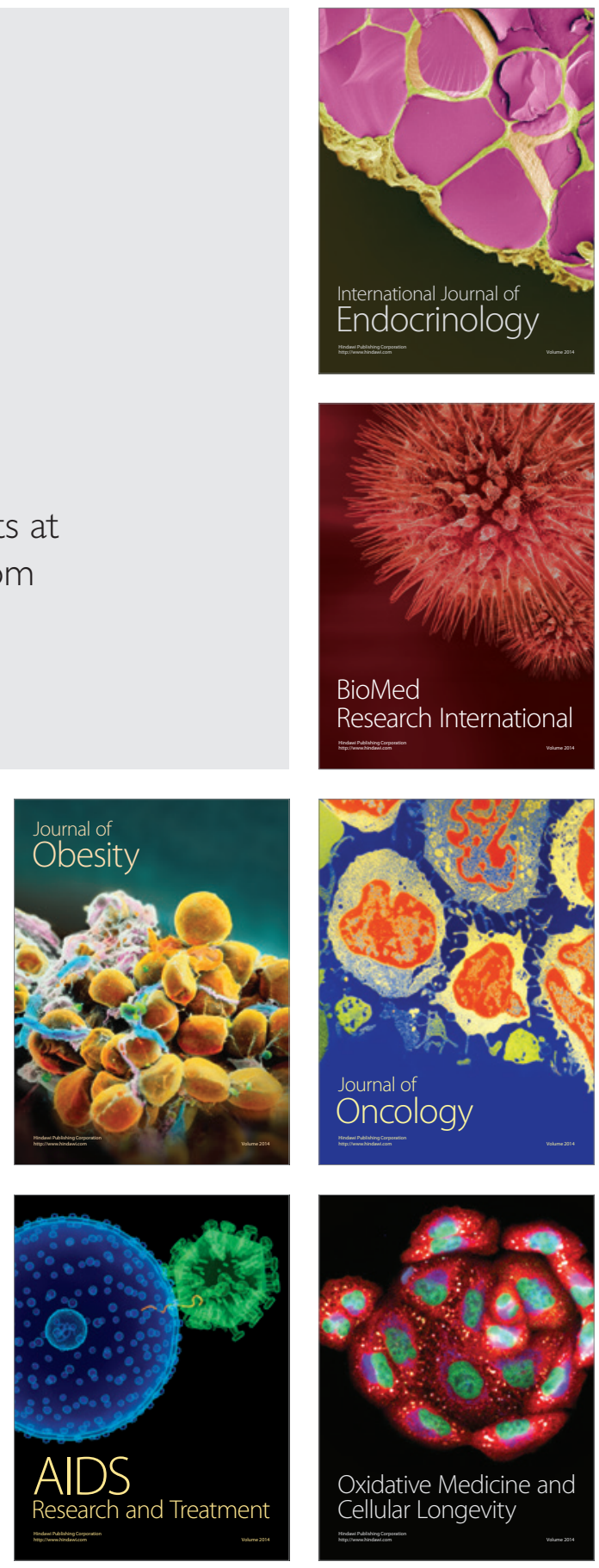